Transaction

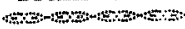

(Received May 11. 1994)

\title{
Reswelling Capability of Pulp Fibers in Paper Sheet
}

\author{
Yuji Matsuda*1 and Fumihiko Onabe ${ }^{* 2}$ \\ *1 Tokushu Paper Mfg., Co., Ltd., Technical Laboratories, 501 Honjyuku. Nagaizumi, Sunto, Shizuoka, Japan 401 \\ ${ }^{* 2}$ Faculty of Agriculture. The University of Tokyo, 1-1.2 Yayoi, Bunkyo, Tokyo, Japan 113
}

\begin{abstract}
Water-reswelling capability of pulp fibers was studied by water retention value applied to paper sheet (WRV-PS) Optimum conditions for determining WRV.PS were first examined, and the WRV.PS obtained by centrifugation at $3000 \mathrm{G}$ for $15 \mathrm{~min}$ can be regarded as a peculiar value for characterizing reswelling properties of paper sheets. Effects of beating, couching, pressing and drying in handsheet-making on reswelling capability of paper sheet were sensitively and clearly detected by the WRV.PS, in comparison with equilibrium moisture content or specific surface area. A decrease in WRVs.PS by pressing and/or drying reflected the formation of hy. drogen bonds of pulp fibers in paper sheet. Furthermore, the decrease in WRVs.PS or the formation of hydrogen bonds in pulp fibers accurred in pressing or dried paper web at water content below the fiber saturation point. Therefore, WRV.PS is widely applicable to evaluation of reswelling properties of paper sheet
\end{abstract}

\section{Introduction}

Reswelling capability of paper sheet by moisture or aqueous solutions is significant for post-treatments such as surface sizing and coating. Reswelling treatments of paper lead to partial cleavage of inter- and intra-fiber bonding and to the resultant relaxation of internal stress in paper. These changes, in turn, bring about alterations in paper sheet properties such as thickness, pore volume, roughness, etc., resulting in remarkable effects on mechanical and optical properties of paper sheet [1-6] Thus, many studies have been reported for elucidating reswelling mechanisms of paper sheet and developing de. termination methods of swelling degrees. Hoyland and Howarth [7] described a technique based on electric con. ductivity for measuring swelling degrees of paper. Skow. ronski et al. (8) presented a method for measuring the swelling pressure of paper

As to swelling of pulp fibers, relationships between swelling degrees and paper properties have been exten. sively studied. Freeness and WRV, which are practically used for evaluating swelling degrees of pulp fibers, fiber saturation points (FSPs), surface area, and others are be lieved to reflect more or less swelling degrees of pulp $\mathrm{fi}$. bers. FSP values determined by the solute-exclusion method was greatly influenced by pulping process, pulp yields, beating, and drying and rewetting treatments of pulp sheet $[9,10]$. Scallan and Carles (11) demonstrated that water retention values (WRVs) of pulp fibers were almost equal to FSPs, when WRVs were determined by centrifugation at $900 \mathrm{G}$ for $30 \mathrm{~min}$. Tensile strength of paper increased with an increase in WRV or FSP of bleached kraft pulp $[10,12]$. Thus, WRV is one of the suitable methods for evaluating the swelling degrees for, at least, pulp fibers under wet conditions.

In this paper, therefore, the applicability of WRV to paper sheet (WRV.PS) was first examined for evaluation of pulp fibers in paper sheet by comparison with specific surface area and equilibrium moisture content of paper sheet. Then the relationships between reswelling capability of pulp fibers in paper sheet and either beating degrees of original pulp fibers or drying treatments of paper sheet were studied in terms of formation of stable hydrogen bonds in pulp fibers during drying process.

\section{Experimental}

\subsection{Sample Preparation}

Hardwood bleached kraft pulp with never-dried and dry lap forms was commercially available. Handsheets were prepared from the pulp beaten to various degrees by a PFI mill, according to the standard method includ. ing the restraint drying at $20{ }^{\circ} \mathrm{C}$ and $65 \%$ relative 
Table 1 Physical Properties of Handsheets Prepared from Pulps Beaten to Various Degrees

\begin{tabular}{cccc}
\hline $\begin{array}{c}\text { Freeness } \\
(\mathrm{mL} \mathrm{CSF})\end{array}$ & $\begin{array}{c}\text { Bone-dry basis } \\
\text { weight }\left(\mathrm{m}^{2} / \mathrm{g}\right)\end{array}$ & $\begin{array}{c}\text { Thickness } \\
(\mathrm{mm})\end{array}$ & $\begin{array}{c}\text { Apparent } \\
\text { density }\end{array}$ \\
\hline 670 & 58.1 & 0.117 & 0.50 \\
457 & 59.3 & 0.090 & 0.66 \\
401 & 60.5 & 0.089 & 0.68 \\
317 & 59.4 & 0.085 & 0.70 \\
249 & 55.7 & 0.077 & 0.72 \\
\hline
\end{tabular}

humidity. Drying at $60-65^{\circ} \mathrm{C}$ and $120.125^{\circ} \mathrm{C}$ was carried out by means of a drying cylinder. Physical properties of handsheets conditioned at $20{ }^{\circ} \mathrm{C}$ and $65 \%$ rela. tive humidity, thus prepared, were listed in Table 1.

\subsection{WRV of Pulp and Paper Sheet}

WRVs of pulps having various beating degrees were measured by the conventional centrifugation method at $20{ }^{\circ} \mathrm{C}[13,15]$. For measurement of WRV.PS, the paper sheet was cut into five pieces with $2.0 \mathrm{~cm}$ square, and these pieces were immersed in deionized water at $20{ }^{\circ} \mathrm{C}$ for $1.24 \mathrm{~h}$. Then the five wet paper-pieces were piled up on a glass-filter for centrifugation. It was confirmed that WRVs-PS were independent on number of sheets thus piled up on the glass-filter. After centrifugation, weight of pulps or paper sheets including water was immediately measured, and then dry weight was measured after drying at $105{ }^{\circ} \mathrm{C}$ for $3 \mathrm{~h}$. WRV.PS was obtained from the following equation.

$$
\text { WRV.PS }(\%)=\frac{W_{\text {wet }}-W_{d r y}}{W_{d r y}} \times 100
$$

Where, $W_{\text {wat }}$ is the weight of the sample after centrifugation, and $W_{\text {dry }}$ is that after oven-drying. WRVS-PS shown in this paper were obtained as mean value of three measurements. The force of centrifugation was calculated by the general method [13]

\subsection{Specific Surface Area of Pulp and Paper Sheet}

Specific surface area of pulps and paper sheets were determined by the nitrogen adsorption method after solvent-exchange drying. The wet beaten or unbeaten pulp containing excess water or the swollen paper sheet with excess water was washed with dry methanol, and the residual water in the sample was removed by soaking the sample in dry methanol. During the soaking for 1 day, methanol was exchanged to fresh one three times, and methanol was subsequently replaced by $n$ pentane.
After the exchange to fresh $n$ pentane three times for 1 day soaking, $n$ pentane was removed from the sample by flushing a stream of dry nitrogen gas to the sample fol. lowed by drying in vacuo at room temperature for $24 \mathrm{~h}$. The nitrogen-adsorption isotherms were obtained from the relationship between pressure of nitrogen gas and weight of nitrogen adsorbed on the sample. Specific sur. face area of the sample was calculated, according to the Brunauer-Emmet-Teller adsorption theory [15].

\subsection{Equilibrium Moisture Content}

Paper sheets were conditioned at various temperature and various relative humidity (R. H.) for 2 days, and equilibrium moisture content of paper sheets after these treatments were measured. The conditions used were as follows; $20^{\circ} \mathrm{C}$ and $65 \%$ R. H. $20{ }^{\circ} \mathrm{C}$ and $90 \%$ R.H., $30{ }^{\circ} \mathrm{C}$ and $90 \% \mathrm{R}, \mathrm{H}$., and $40{ }^{\circ} \mathrm{C}$ and $90 \% \mathrm{R} . \mathrm{H}$. The values were obtained as mean values of three sheets with 0.02 $\mathbf{m}^{2}$.

\section{Results and Discussion}

\subsection{Conditions of Centrifugation}

Fig.1 shows the relationship between centrifugation time and WRVS-PS of handsheets prepared from pulp with $457 \mathrm{~mL}$ of Canadian Standard Freeness (C. S. F.). WRV.PS largely decreased within the first $15 \mathrm{~min}$, and

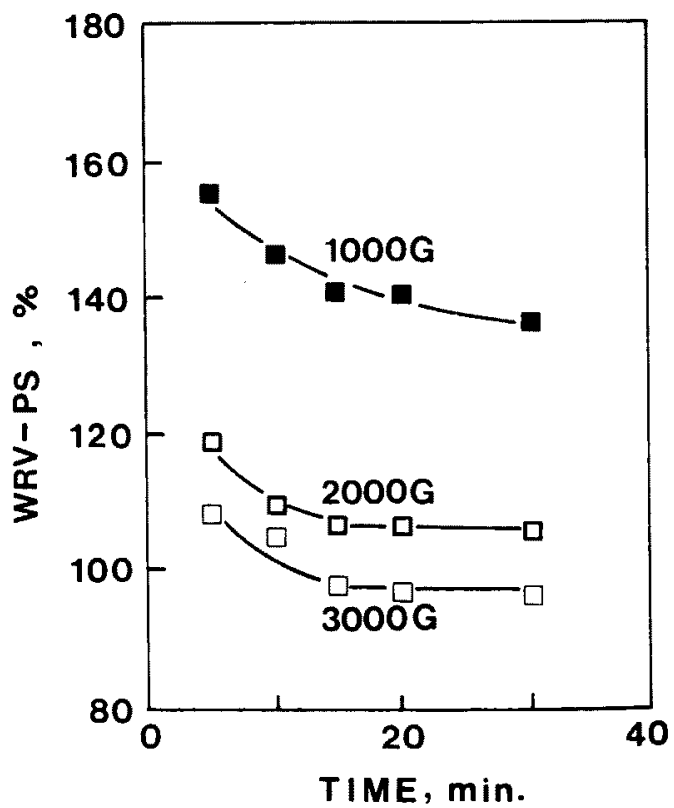

Fig. 1 Relationship between centrifugal time and WRV. PS of handsheet prepared from pulp beaten to $457 \mathrm{~mL} \mathrm{C}$. S. F. 


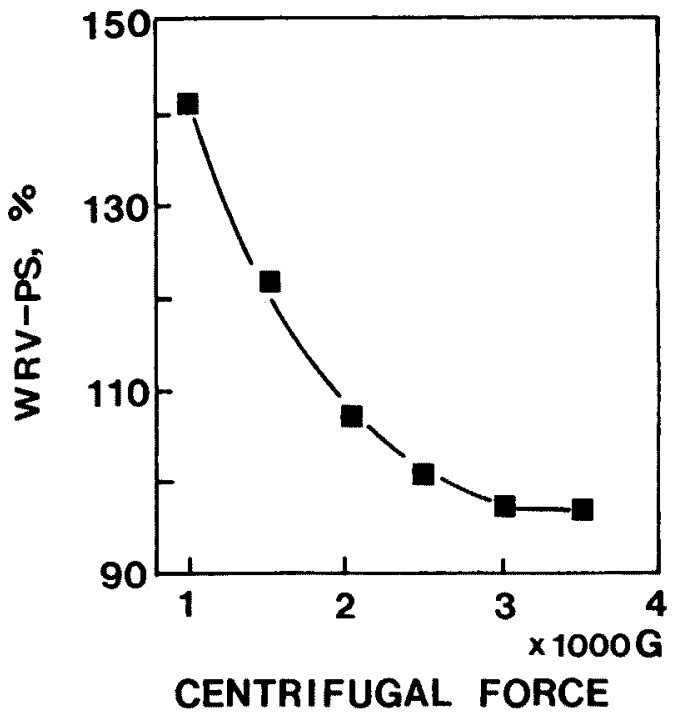

Fig. 2 Variation in WRV.PS of handsheet prepared from pulp beaten to $457 \mathrm{~mL} \mathrm{C.} \mathrm{S.} \mathrm{F.} \mathrm{as} \mathrm{a} \mathrm{function} \mathrm{of} \mathrm{cen-}$ trifugal force. Centrifugal time was fixed to $15 \mathrm{~min}$.

then decreased slightly at $1000 \mathrm{G}$ or became nearly constant for the centrifugation treatments at 2000 and 3000

G. Thus, the centrifugation of 15 min seemed to be suffi. cient to obtain the minimum WRV.PS of paper sheet at $2000 \mathrm{G}$ or more.

The effect of centrifugal force varying from 1000 to $3500 \mathrm{G}$ within $15 \mathrm{~min}$ on WRV.PS was examined for the same paper sheet. (Fig. 2) WRV-PS remarkably decreased between 1000 and $2500 \mathrm{G}$, and then became constant by centrifugation at more than $3000 \mathrm{G}$. Thus, the nearly minimum WRV.PS obtained by centrifugation of wet paper sheets at $3000 \mathrm{G}$ for $15 \mathrm{~min}$ using a centrifugal separator in our laboratory can be regarded as a characteristic WRV.PS. This so-called equilibrium WRV, therefore, may be applicable to paper sheet for evalua. tion of swelling degrees, which reflect formation of hyd. rogen bonding or hornification.

\subsection{Effects of Beating of Pulp Fibers on WRVs-PS}

It is known that moisture content of paper sheet is related to their accessibility to water vapor, and thus these values also must reflect number or hydrogen bonds formed during drying and other post-treatments of paper sheet. Then moisture content of paper sheets prepared from pulps with various C. S. F. were examined, and Fig. 3 shows WRV and moisture content of the paper sheets versus pulp freeness. WRVs of paper sheets clearly and

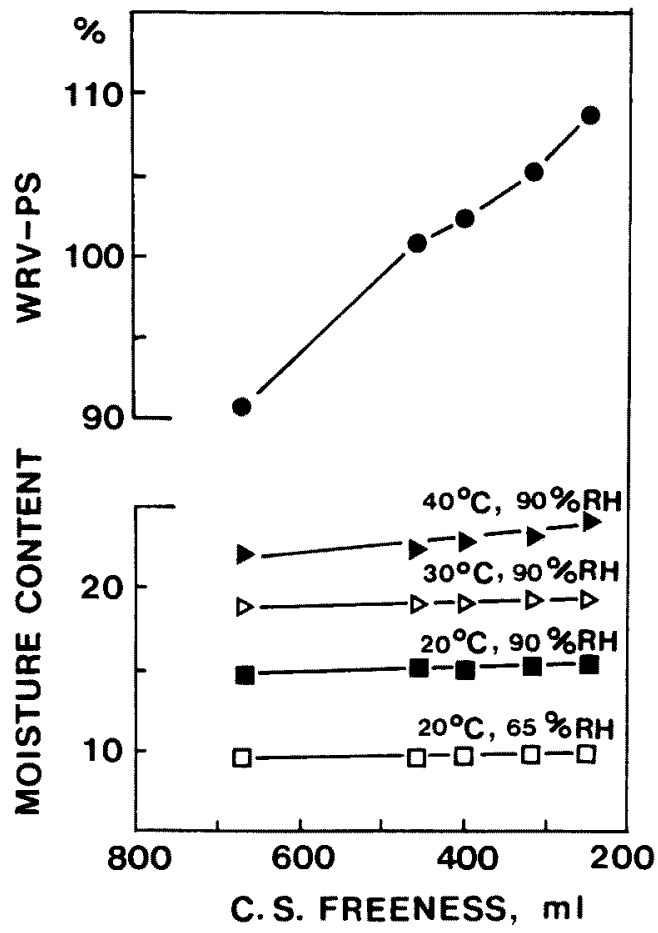

Fig. 3 WRV-PS and equilibrium moisture content of handsheets prepared from pulps beaten to various de. grees.

sensitively increased from $90 \%$ to $110 \%$ with a decrease in C.S.F. of the original pulps. In contrast, the equilibrium moisture content of paper sheets slightly increased. When freeness of pulp used for preparation of the paper sheets varied from 670 to $249 \mathrm{~mL} \mathrm{C.} \mathrm{S.} \mathrm{F.,} \mathrm{the} \mathrm{increase}$ in equilibrium moisture content was within $2 \%$ even at $40{ }^{\circ} \mathrm{C}$ and $90 \%$ R.H. Thus, WRV-PS could sensitively and clearly evaluate differences in accessibility of pulp fibers in paper sheet to water. It is expected, therefore, that small amount of stable hydrogen bonds, which are formed in pulp fibers or interfiber bonding during drying treatments of paper sheets, may be detected by the WRV method.

\subsection{WRV of Pulp and Paper Sheet}

Fig. 4 shows relationships between C.S.F. of the original pulps and either WRVS of the original pulps or paper sheets immersed in water for 1 and $24 \mathrm{~h}$. A part of handsheets immersed in water for $24 \mathrm{~h}$ were disinte. grated to single fibers, and WRVs of these fibers also were measured. (Fig. 4) As being expected, large differences in WRVs were observed between the original 


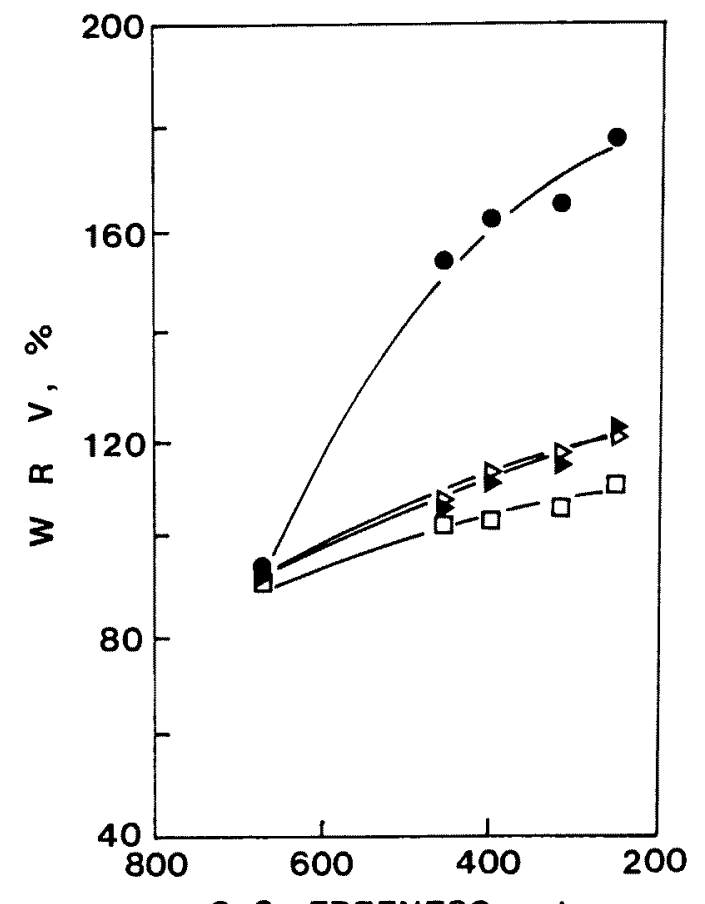

C. S. FREENESS, $\mathrm{ml}$

Fig. 4 WRVs of original pulps and handsheets as a function of C. S .F. Original pulp: (O), handsheet soaked in water for $1 \mathrm{~h}:(\square)$ and $24 \mathrm{~h}:(D)$, and pulp fibers obtained from the handsheet soaked in water for $24 \mathrm{~h}$ followed by disintegration (A).

pulps and paper sheets, when the beaten pulps were used. This result suggests that stable hydrogen bonds are formed in paper sheets even during drying of paper web at $20{ }^{\circ} \mathrm{C}$ and $65 \%$ R.H. Simultaneously, Fig. 4 also shows that stability of the hydrogen bonds are various; some of hydrogen bonds formed during the handsheet. making are rapidly cleaved by the water-soaking treatment within $1 \mathrm{~h}$, some of the rest hydrogen bonds are gradually cleaved, and others may be almost stable to water at room temperature. The formation of stable hy. drogen bonds increased with a decrease in C. S. F. of the original pulps. It is noteworthy that the paper sheet prepared from the unbeaten pulp had almost equal WRV.PS to that of the original pulp, indicating that no stable hy. drogen bonds were formed for this sheet during handsheet-making.

As shown in Fig. 4, WRVs of pulp fibers prepared from the paper sheets by disintegration were almost equal to those of the original paper sheets. This result indicates that the stable hydrogen bonds, which might be related to hornification, were not affected by disintegra. tion.

\subsection{Specific Surface Area of Pulp and Handsheet}

Fig. 5 shows the effects of beating on specific surface area of pulps and of handsheets prepared from the pulps. These swollen pulps and handsheets were solvent-exchanged from methanol to $n$-pentane, and were dried in vacuo. These specific surface areas of pulps were almost equal to those reported for dry lap pulps, and were much smaller than those of never-dried pulps $\left(100 \sim 200 \mathrm{~m}^{2} / \mathrm{g}\right)$ [14]. The differences in specific surface areas between pulps and handsheets indicate the formation of stable hydrogen bonds in pulp fibers of paper sheet by drying of paper web at $20^{\circ} \mathrm{C}$ and $65 \%$ R.H. Compared with the results in Fig. 4, the differences in specific surface areas between the original pulps and the paper sheets were smaller than those in WRVs, when the beaten pulps were used. Since complete solvent-exchange from water to organic solvents must be difficult to be achieved, a part of swollen micro-structures in pulps and paper sheets may be lost during the procedure of the solvent. exchange-drying. On the other hand, WRV can detect water-accessible region of paper sheet which is sensitive even towards mild drying.

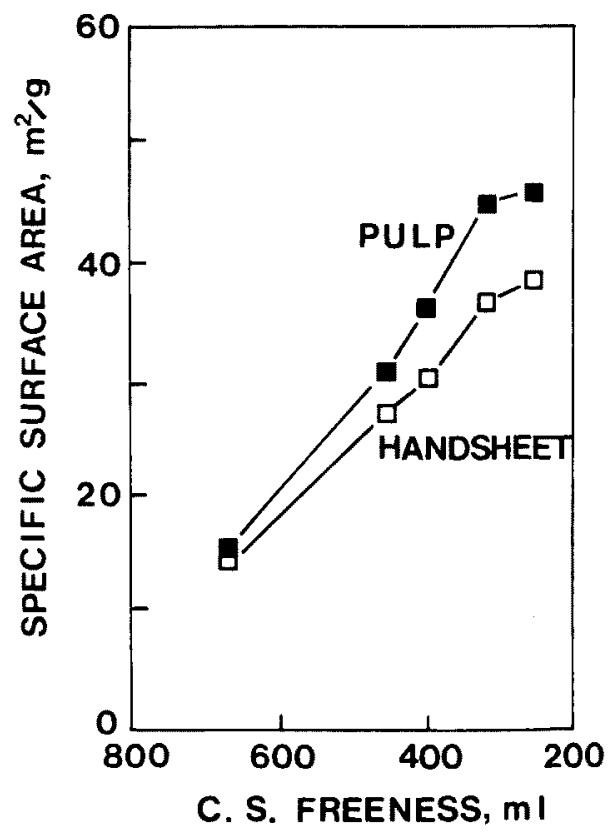

Fig. 5 Relationship between C. S. F. and specific sur. face area of swollen pulps and swollen handsheets. Meas. ured after solvent-exchange drying. 


\subsection{WRVs of Solvent-Exchange-Dried and Freeze-Dried Pulp}

Fig. 6 shows WRVs of solvent-exchange-dried and freeze-dried pulps in comparison with those of handsheet prepared from original pulp. WRVs of these dried pulps and handsheets were determined after immersing in water for $24 \mathrm{~h}$. WRVs of solvent-exchange-dried and freezedried pulps were clearly higher than those of handsheets dried even at $20{ }^{\circ} \mathrm{C}, 65 \% \mathrm{R}$. H. This result indicates that a part of hydrogen bonds formed in the handsheet by drying from wet web at $20{ }^{\circ} \mathrm{C}, 65 \% \mathrm{R}$. H. easily became stable hydrogen bonds, compared with solvent-exchange drying and freeze-drying. WRVs of solvent-exchange dried and freeze-dried pulps were, however, smaller than that of original pulp; fine swollen structures of original pulp fibers could not be maintained even by these drying procedures.

\subsection{Effects of Drying Treatment of Paper Sheet on Res- welling Capability}

Fig. 7 shows how drying conditions affect WRVs.PS of handsheets prepared from a never-dried pulp with differ. ent beating degrees. These WRVs-PS of handsheets after pressing or drying were determined after immersing in water for $1 \mathrm{~h}$. After the pressing treatment, decrements in WRVs-PS of unbeaten and beaten pulps were $11 \%$ and $28 \%$, respectively. This result suggested that a part of hydrogen bonds were formed by dewatering effect in pressing treatment. and some of the hydrogen bonds became stable ones. Fig. 7 shows that WRVs.PS of hand.

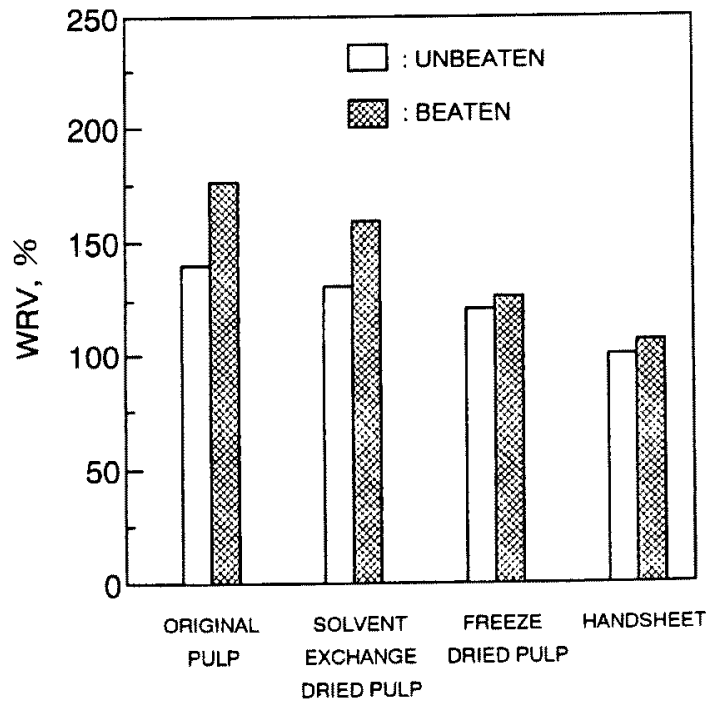

Fig. 6 Effect of drying methods of pulp on WRV

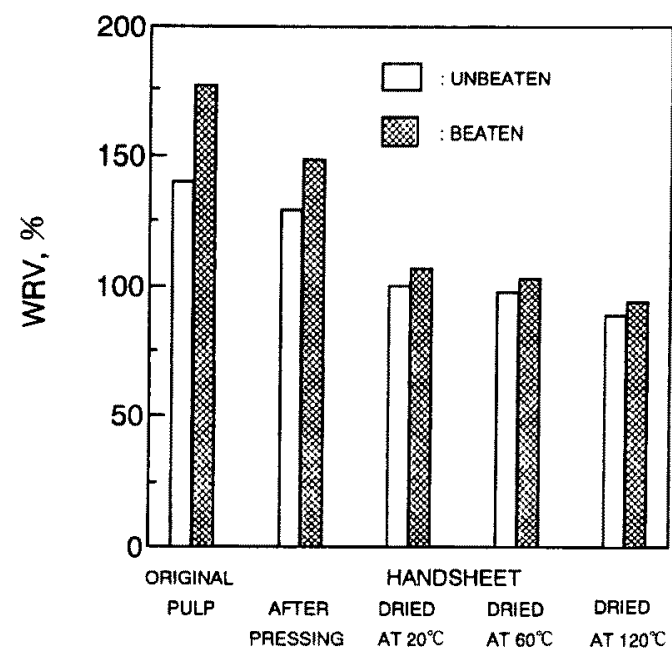

Fig. 7 Effect of drying methods of handsheet on WRV.

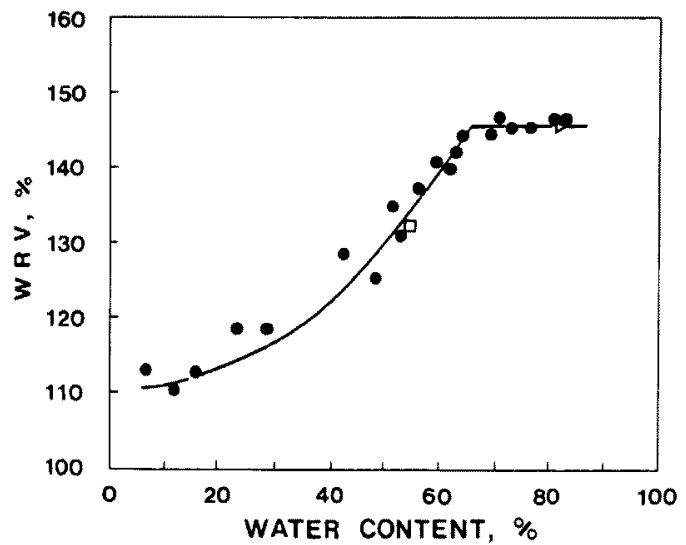

Fig. 8 Relationship between water content of pulp and WRV.

WRVs.PS of handsheet after couching: (D), and after pressing: ( $\square$ )

sheets after drying decreased with temperature. Moisture contents of handsheets after drying treatments at 20,60. and $120{ }^{\circ} \mathrm{C}$ were $8.5 \cdot 9.0 .5 .1-5.5$, and $2.5 \cdot 3.3 \%$, respectively. This result show's that the stable hydrogen bonds increased with drying temperature.

\subsection{Effect of Water Content of Pulp on Reswelling Capability}

The relation between WRV.PS and reswelling capabil. ity, which is related to formation of the stable hydrogen bonds, was examined by the WRV measurement of pulp. In order to prepare pulp sample with various water contents, a pulp mat with about $5 \mathrm{~mm}$ thickness was formed 
on a glass filter, and was dried by streaming air through the pulp mat at room temperature using suction filtra. tion. Fig. 8 shows relationship between water content of pulp and WRV of the pulp immersed in water for $1 \mathrm{~h}$. WRVs were constant for pulp with $65.87 \%$ water content, and indicating that no stable hydrogen bonds were formed in these pulp. When water content decreased below $65 \%$, reswelling capability began to decrease. Therefore the so-called hydrogen bonds began to be formed at water content below $65 \%$, which was probably the fiber saturation point for this paper. As shown in Fig. 8, there are no differences of WRVS between handsheet after couching or pressing and pulp dried by streaming air. This result indicates no effect of compression of fiber by couching and pressing on reswelling capability.

\section{References}

1. J. A. Bristow, Syensk Papperstidn., 74, 645 (1971).

2. J. A. Bristow, Suensk Papperstidn., 75, 847 (1972).

3. Y. Matsuda, S. Kuga, F. Onabe, and M. Usuda, Japan Tappi, 46, 323 (1992).

4. Y. Matsuda, S. Kuga, F. Onabe, and M. Usuda, Japan Tappi, 46, 72 (1992).
5. P. Lepoutre, J. Skowronski, and W. Bichard, Proceedings of 1986 Coating Conference, TAPPI PRESS, Atlanta, p. 113.

6. J. Skowronski and P. Lepoutre, Tappi, 68, 98 (1985).

7. R. W. Hoyland and P. Howarth, Fundamental Prop. erties of Paper Related to Its Uses (F. Bolam, Ed), Technical Division, B.P. \& B.I.F., London, 1976, p. 345 .

8. J. Skowronski, P. Lepoutre, and W. Bichard, Tappi, 71, 125 (1988).

9. J. E. Stone and A. M. Scallan, Tappi, 50, 496 (1968).

10. 1. E. Stone and A. M. Scallan, and Abrahamson, B., Svensk Papperstidn., 71, 687 (1968).

11. A. M. Scallan and J. E. Carles, Suensk Papperstidn, 75, 699 (1972).

12. G. Jayme, A. F. Ghoneim, and H. Kruger, Das Papier 20. 357 (1966).

13. G. Jame, Tappi 41, 180A (1958).

14. J. E. Stone and A. M. Scallan, Pulp and Paper Mag. Can, 66, T-407 (1965).

15. F. Edward, J. G. Thode, Jr. Bergomi, and E. U. Rene, Tappi 43, 505 (1960). 